\section{Intraductal necrosectomy for pancreatic walled-off necrosis using novel single-operator pancreato-}

\section{scope}

A digital catheter-based single-operator cholangiopancreatoscope (SpyGlass DS Direct Visualization System; SPY DS, Boston Scientific) has recently become available. The scope of the SPY DS model shows marked improvements over the conventional SpyGlass system: (i) insertion into the biliary tract is easier because of the tapered tip; (ii) better visualization is obtained with the $120^{\circ}$ digital field of view; and (iii) newly added injection and suction functions may be carried out through a two-port adaptor. This system thus allows diagnosis by direct visualization, and performance of various therapeutic interventions. Herein, we present technical tips for intraductal necrosectomy for infected pancreatic walled-off necrosis (WON) using a novel single-operator pancreatoscope.

A 54-year-old-man was admitted to our hospital for treatment of pancreatic WON. Although oral intake was begun because of disappearance of clinical symptoms and improvement of inflammation metrics, there was recurrence of acute pancreatitis. Despite another 15 days of conservative treatment, spiking fever and elevated inflammation metrics remained. On computed tomography, WON was seen in the pancreatic tail ( Fig. 1). We first attempted endoscopic ultrasound (EUS)-guided drainage, but the distance between the stomach and the pancreatic WON was too great and drainage could not be established. We therefore performed endoscopic retrograde cholangiopancreatography (ERCP). First, we inserted the ERCP catheter into the main pancreatic duct and the contrast medium was injected. A communication between the pancreatic WON and the main pancreatic duct was identified ( Fig.2). On insertion of the SPY DS scope into the pseudocyst, a large region of necrotic tissue was seen ( $\bullet$ Fig.3). Necrosectomy was therefore performed using a SpyBite device (Boston Scientific) ( $\bullet$ Fig.4). After this procedure, the pseudocyst disappeared, and clinical results improved. This novel, single-operator cholangiopancreatoscope has a clinical impact not only on diagnosis or targeted

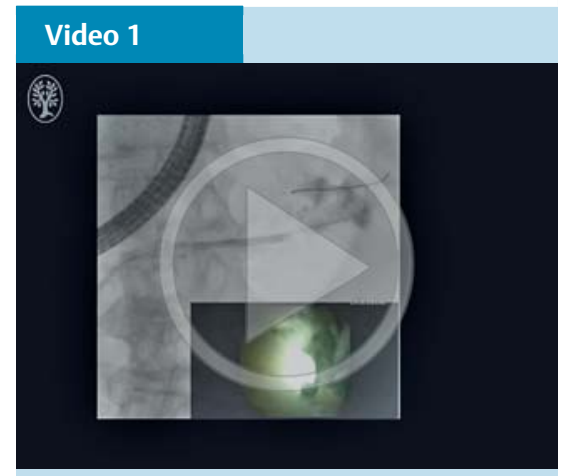

Intraductal necrosectomy for pancreatic walled-off necrosis (WON). A digital single-operator pancreatoscope is inserted into the main pancreatic duct, revealing a massive area of necrotic tissue. Necrosectomy is performed using the SpyBite forceps biopsy device.

biopsy under direct visualization, but also for interventional treatments such as intraductal necrosectomy.

Endoscopy_UCTN_Code_TTT_1AR_2AI

Competing interests: The authors declare no conflict of interest.

\section{Takeshi Ogura, Wataru Takagi, Saori Onda, Tastsushi Sano, Kazuhide Higuchi}

Second Department of Internal Medicine, Osaka Medical College, Osaka, Japan

\section{Bibliography}

Dol http://dx.doi.org/

10.1055/s-0042-118166

Endoscopy 2016; 48: E343

(c) Georg Thieme Verlag KG

Stuttgart · New York

ISSN 0013-726X

\section{Corresponding author}

\section{Takeshi Ogura, MD}

2nd Department of Internal Medicine,

Osaka Medical College

2-7 Daigakuchou, Takatsukishi

Osaka 569-8686

Japan

Fax: +81-72-6846532

oguratakeshi0411@yahoo.co.jp

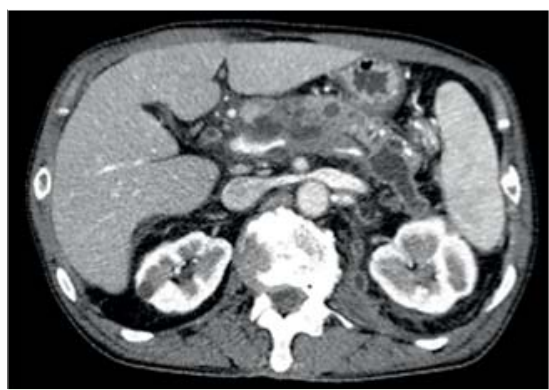

Fig. 1 Pancreatic walled-off necrosis (WON) seen in the pancreatic tail, at computed tomography in a 54-year-old man.

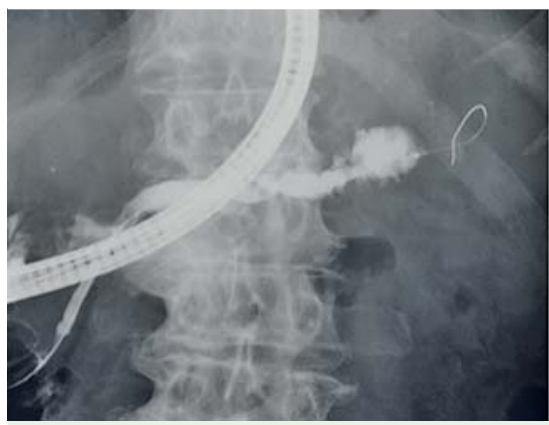

Fig. 2 Communication between the pancreatic WON and the main pancreatic duct, seen on pancreatography.

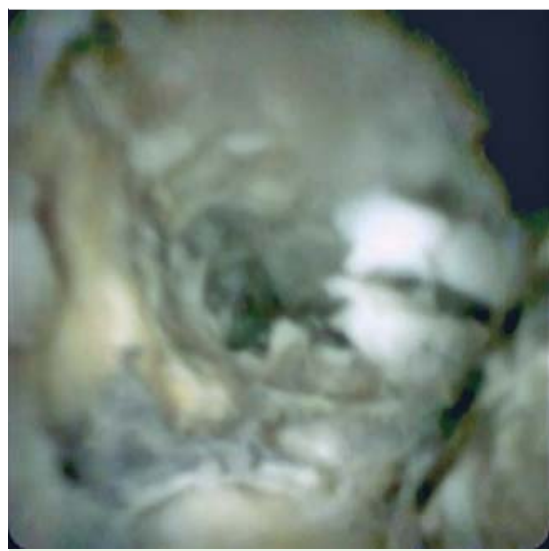

Fig.3 A massive region of necrotic tissue is seen through the intraductal pancreatoscope.

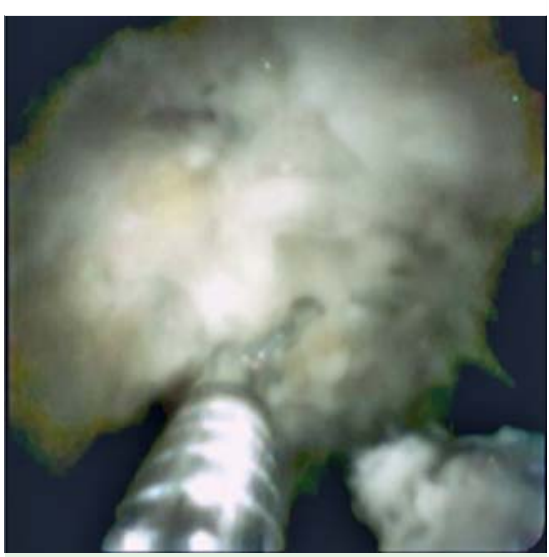

Fig. 4 Necrosectomy of the pancreatic walled-off necrosis is performed using a SpyBite device. 